OPEN ACCESS

Edited by:

Sajeewa S. N. Maharachchikumbura, University of Electronic Science and

Technology of China, China

Reviewed by:

Vishukumar Aimanianda, Institut Pasteur, France

Nimal Adikaram,

National Institute of Fundamental

Studies (NIFS), Sri Lanka

*Correspondence:

Niroshini Gunasinghe

Niroshini.gunasinghe@usq.edu.au

Specialty section: This article was submitted to

Fungal Pathogenesis,

a section of the journal

Frontiers in Cellular

and Infection Microbiology

Received: 09 March 2021

Accepted: 19 April 2021

Published: 04 June 2021

Citation:

Gunasinghe N, Barbetti MJ,

You MP, Dehigaspitiya P

and Neate $S$ (2021) Dimorphism

in Neopseudocercosporella

capsellae, an Emerging Pathogen

Causing White Leaf Spot

Disease of Brassicas.

Front. Cell. Infect. Microbiol. 11:678231

do: 10.3389/fcimb.2021.678231

\section{Dimorphism in Neopseudocercosporella capsellae, an Emerging Pathogen Causing White Leaf Spot Disease of Brassicas}

\author{
Niroshini Gunasinghe ${ }^{1 *}$, Martin J. Barbetti ${ }^{2}$, Ming Pei You ${ }^{2}$, Prabuddha Dehigaspitiya ${ }^{1}$ \\ and Stephen Neate ${ }^{3}$ \\ ${ }^{1}$ Centre for Crop Health, Institute for Agriculture and the Environment, Research and Innovation Division, University of \\ Southern Queensland, Toowoomba, QLD, Australia, 2 School of Agriculture and Environment and the Institute of Agriculture, \\ Faculty of Science, The University of Western Australia, Crawley, WA, Australia, ${ }^{3}$ School of Agriculture, Food and Wine, \\ Faculty of Sciences, University of Adelaide, Urrbrae, SA, Australia
}

White leaf spot pathogen: Neopseudocercosporella capsellae causes significant damage to many economically important Brassicaceae crops, including oilseed rape through foliar, stem, and pod lesions under cool and wet conditions. A lack of information on critical aspects of the pathogen's life cycle limits the development of effective control measures. The presence of single-celled spores along with multi-celled conidia on cotyledons inoculated with multi-celled conidia suggested that the multi-celled conidia were able to form single-celled spores on the host surface. This study was designed to demonstrate $N$. capsellae morphological plasticity, which allows the shift between a yeast-like singlecelled phase and the multi-celled hyphal phase. Separate experiments were designed to illustrate the pathogen's morphological transformation to single-celled yeast phase from multi-celled hyphae or multi-celled macroconidia in-vitro and in-planta. Results confirmed the ability of $N$. capsellae to switch between two morphologies (septate hyphae and single-celled yeast phase) on a range of artificial culture media (in-vitro) or in-planta on the host surface before infection occurs. The hyphae-to-yeast transformation occurred through the production of two morphologically distinguishable blastospore (blastoconidia) types (meso-blastospores and micro-blastospores), and arthrospores (arthroconidia).

Keywords: Arthroconidia, Blastoconidia, Brassica, dimorphism, morphological transformation, N. capsellae, white leaf spot

\section{INTRODUCTION}

Dimorphic fungi are capable of assuming two distinct morphologies during their life cycle, switching between a single-celled yeast form and a multi-celled hyphal form (Gauthier, 2015). Dimorphism is a highly synchronized, reversible response to an external stimulus posed by the environment (Lin et al., 2015). The majority of dimorphic fungi belong to the class Ascomycete or their 'Imperfect' relatives (Gauthier, 2015), and morphogenesis is widespread among pathogenic fungi of either mammals, plants, or insects (Gauthier, 2015). Well-known dimorphic 
phytopathogenic fungi such as Taphrina deformans, the cause of peach leaf curl disease, and Ophiostoma novo-ulmi, the cause of Dutch elm disease, have had major adverse impacts on agriculture or the urban landscape, respectively (Gauthier, 2015).

In dimorphic fungi, yeast phase development occurs usually in response to a change in growth condition and/or nutritional status of the growth medium (Odds and Kerridge, 1985; Lin et al., 2015). Although diverse stimuli, including pheromones, plant lipids, plant hydrophobicity, $\mathrm{pH}$, nitrogen, and quorum sensing can induce the transition of yeast-to-mycelium or vice versa in fungal morphogenesis in plant pathogenic fungi (Orlowski, 1994), several human fungal pathogens are solely thermally dimorphic, where temperature alone induces the morphological transformation (Orlowski, 1994; Gauthier, 2015). The search for internal factors that regulate morphogenesis or external factors that stimulate this dimorphic switch is a rapidly growing area of research, due in part to the availability of novel microscopy and molecular tools in the past decade (Gauthier, 2015). Such studies have revealed that pathogenicity, virulence, and lifecycle of dimorphic fungal pathogens are closely interrelated, and that pathogenicity may be limited to one of the alternative morphologies (Gauthier, 2015; Lin et al., 2015).

Neopseudocercosporella capsellae, the cause of white leaf spot disease, causes significant damage to many economically important Brassicaceae crops, including oilseed rape/canola, vegetable, condiment, and fodder species (Barbetti and Sivasithamparam, 1981; Petrie, 1985; Cerkauskas et al., 1998; Gunasinghe et al., 2020). The pathogen produces foliar, stem, and pod lesions under favourable weather conditions (Petrie and Vanterpool, 1978) causing yield losses in the range of $24-30 \%$ in oilseed brassicas (Penaud, 1987; Barbetti and Khangura, 2000; Murtza et al., 2021). While the pathogen distribution is worldwide, it is most destructive in regions with cool and wet climates, such as occur in France (Perron and Nourani, 1990; Penaud and Walker, 2015), the United Kingdom (Inman et al., 1993), Canada (Petrie and Vanterpool, 1978), the United States of America (Ocamb et al., 2015) and Australia (Gunasinghe et al., 2016d; Van de Wouw et al., 2016; Gunasinghe et al., 2017; Murtza et al., 2018). Over recent decades, there has been an increase in white leaf spot disease in some countries, such as the United Kingdom following wetter/warmer winters in the 1990s (Inman et al., 1993).

Despite being a common Brassica pathogen, important knowledge gaps exist in the N. capsellae-Brassica pathosystem (Gunasinghe et al., 2020), particularly on critical aspects of its epidemiology. This is in part from its very slow growth rate on artificial media (Crossan, 1954) and its secretion of cercosporin, a non-host specific, photo-activated toxin into both artificial media and during the early infection process in host tissues (Gunasinghe et al., 2016b). Air-dispersed ascospores produced by the teleomorph are responsible for the disease initiation and long-distance pathogen dispersal in the United Kingdom (Inman et al., 1992). However, elsewhere, most N. capsellae populations are anamorphic and thought to be clonal, where aspects of $N$. capsellae pathogenicity, disease initiation, spread, and epidemic development are not fully described and/or understood (Gunasinghe et al., 2020). For example, on rapeseed cotyledons, Australian isolates of $N$. capsellae can be observed as hyphae, as large multi-celled conidia, and what appeared to be singlecelled spores that are able to reproduce by budding (Gunasinghe unpub). This suggests that a morphologic shift between the yeast phase and the hyphal form likely occurs for $N$. capsellae. Its relevance is that morphologic shift between the yeast phase and the hyphal form in other pathogenic fungi is essential for maintaining pathogenicity (Orlowski, 1994). Further, Lin et al. (2015) noted, a thorough understanding of the life cycle of dimorphic pathogens is required if they are to be effectively controlled. Hence, studies were undertaken to determine if $N$. capsellae is dimorphic and able to switch between a singlecelled yeast form and a multi-celled hyphal form in-vitro or inplanta on host leaves.

\section{METHODS}

\section{Pathogen Isolates}

Three single-spored isolates of $N$. capsellae (UWA Wln-10, UWA Wlj-3, and UWA Wlra-7), stored as lyophilized ampoules containing the living pathogen preserved on vacuum dried agar cultures (Bazzigher and Kanzler, 1985) at room temperature, were obtained from the University of Western Australia (UWA) culture collection. All three isolates were collected within Western Australia. UWA Wln-10 was from infected leaves of B. napus at Bindoon North, UWA Wlj-3 was from diseased $B$. juncea leaves at Shenton Park, and UWA Wlra7 was isolated from infected Raphanus raphanistrum leaves at West Calingiri (Gunasinghe et al., 2016d). Pathogen isolates were revived on Potato Dextrose Agar (PDA - Difco) or Malt Yeast Extract (MEA) plates and then working cultures were maintained as MEA media slants at $4^{\circ} \mathrm{C}$. For in-vitro studies, two isolates of genetically different groups (UWA Wlj-3, and UWA Wlra-7) (Gunasinghe et al., 2016a) were used. When multi-celled conidia were needed, susceptible host plants grown in the field were spray inoculated with a mixture of hyphal fragments of all three isolates, and conidia produced on host plants lesions were collected (Gunasinghe et al., 2014).

\section{Preparation of Mycelial Suspension and Multi-Celled Conidial Suspension for In-Vitro and In-Planta Studies}

To prepare a mycelial suspension, each of the three $N$. capsellae isolates (UWA Wln-10, UWA Wlj-3, and UWA Wlra-7) was sub-cultured onto MEA in Petri Plates and grown for three weeks at $20^{\circ} \mathrm{C}$. Erlenmeyer flasks $(250 \mathrm{~mL})$ containing $150 \mathrm{~mL}$ of Malt Extract Broth (MEB) were inoculated with agar plugs from the growing edges of each $N$. capsellae culture separately and incubated on a rotary platform shaker (Innova ${ }^{\mathrm{TM}} 2100$, New Brunswick Scientific) at $150 \mathrm{rpm}$ and $20^{\circ} \mathrm{C}$. After 3-4 weeks, cultures of all three isolates with abundant mycelial growth were mixed in equal volumes and blended for 5 min (Kambrook Mega Blender, Breville Group Ltd). Mycelial mats in the mixture after 
blending were removed by filtering through sterile gauze. Concentration of the filtered suspension of mycelial fragments containing $90 \mu \mathrm{m}( \pm 10 \mu \mathrm{m})$ length was adjusted to $4 \times 10^{6} \mathrm{~mL}^{-1}$ using a hemocytometer and sterile distilled water (Gunasinghe et al., 2014).

To produce multi-celled conidia, field-grown plants were inoculated with mycelial inoculum. Seeds of highly susceptible, B. juncea genotypes Rohini, Vardan, or Prakash (Gunasinghe et al., 2014) were sown (6 seeds per pot) in sequential batches of 9 pots each, seedlings were grown in a controlled environment room $\left(15^{\circ} \mathrm{C}, 12 \mathrm{~h}\right.$ photoperiod and Photosynthetic Photon Flux Density of $580 \mu \mathrm{molm}^{-2} \mathrm{~s}^{-1}$ ) for 15 to 20 days before transferring into an experimental field plot $(1 \times 0.5 \mathrm{~m})$ at the University of Western Australia, Crawley, Western Australia, where they were fertilized weekly with Thrive ${ }^{\circledR}$ (DuluxGroup (Australia) Pty Ltd), a complete nutrient solution dissolved in water. Beginning at approximately four weeks of age, field plants were sprayinoculated weekly with a mixture of mycelial fragments $(4 \mathrm{x}$ $10^{6}$ fragments $\mathrm{mL}^{-1}$ ) prepared as described above for three consecutive weeks using a handheld and operated aerosol sprayer in the late afternoon to maximize the period of high humidity to favour infections.

After 20 to 25 days post-inoculation, when disease symptoms became apparent, leaves with typical white leaf spot symptoms were collected. Leaves with lesions were gently washed with sterile deionized water (DI) before, lesions were excised and placed into glass vials containing $20-30 \mathrm{~mL}$ of sterile DI. Multi-celled conidia were released by vigorous handshaking for four min. The pieces of the leaf lesions were removed from the glass vials with a sterile pair of forceps and the mixture was centrifuged to pellet the conidia. The supernatant was discarded and the conidial pellet was washed twice in sterile DI water and re-suspended in 2 to $3 \mathrm{~mL}$ of sterile DI water. Multi-celled conidial concentration $\left(4 \times 10^{6} \mathrm{~mL}^{-1}\right)$ was achieved by making adjustments based on hemocytometer counts (Gunasinghe et al., 2016c).

\section{Dimorphism In-Vitro}

In-Vitro Blastospore Formation From N. capsellae Hyphae and Observations of Colony Morphology During Morphological Transformation

Morphological transformation of $N$. capsellae was examined by inoculating UWA Wlj-3, and UWA Wlra-7 on 5 different media: PDA (Difco), MEA (20g, peptone: $6 \mathrm{~g}$, dextrose: $20 \mathrm{~g}$, agar: $15 \mathrm{~g}$, de-ionized water $1 \mathrm{~L}$ ), V-8 juice agar (clarified V-8 juice: $200 \mathrm{~mL}$, $\mathrm{CaCO}_{3}: 3 \mathrm{~g}$, agar $15 \mathrm{~g}$, de-ionized water $\left.1 \mathrm{~L}\right)$, Neutral Dox Yeast Agar (NDYA) $\left(\mathrm{NaNO}_{3}: 2 \mathrm{~g}, \mathrm{KH}_{2} \mathrm{PO}_{4} ; \mathrm{g}, \mathrm{MgSO}_{4}\right.$ : $0.5 \mathrm{~g}, \mathrm{KCL}$ : $0.5 \mathrm{~g}, \mathrm{FeSO}_{4} 0.1 \%$ sol: $10 \mathrm{~mL}$, yeast extract: $0.5 \mathrm{~g}$, sucrose: $30 \mathrm{~g}$, agar: 14g, de-ionised water: 1L), Yeast Extract Peptone Dextrose Agar (YEDPA) (Yeast extract: 10g, peptone: $10 \mathrm{~g}$, dextrose: $20 \mathrm{~g}$, agar $15 \mathrm{~g}$, de-ionised water $1 \mathrm{~L}$ adjusted to $\mathrm{pH}=6$ ) or Water Agar (WA) (agar:15g, de-ionised water $1 \mathrm{~L}$ ) using two inoculation methods (streak plate method and agar plug method). A four week old pure mycelial colony of each isolate on NDY was used for all inoculations.

For the agar plug method, a mycelial plug ( $5 \mathrm{~mm}$ diameter) from the growing edge of the mycelial colony was placed in the middle of a Petri Plate containing PDA, MEA, V-8 juice agar, NDYA, YEDPA, or WA. For the streak plate method, a loop full of mycelial fragments was taken from the growing edge of the colony and dragged over the surface of the plate in a 'zig-zag' formation. There were six single plate replicates for each medium for each inoculation method. Three plates from each media inoculated with each individual inoculation method were incubated at $23^{\circ} \mathrm{C}$, and the other three at $37^{\circ} \mathrm{C}$, in the dark for a maximum of 4 weeks.

Stereo microscopy, light microscopy (LM), and scanning electron microscopy (SEM) techniques were used to document colony and cell morphologies. Colony morphologies of $N$. capsellae on different media incubated at the two temperatures were recorded every other day by examining individual plates. Colonies on plates were further prepared to examine with a Nikon- SMZ1500 stereomicroscope, a Nikon Eclipse Ni-U light microscope, or SEM where necessary.

LM: Cells/hyphae collected by scraping the surface of colonies were mounted on microscope slides and stained with $1 \%$ cotton blue in lactophenol. Slides were studied and photographed (1000x magnification) with a Nikon Eclipse Ni-U light microscope. SEM: Selected colonies were prepared for SEM for further analysis. Thin agar blocks $(2-3 \mathrm{~cm})$ with colonies were cut carefully from the culture plate with a sterile scalpel and placed on a pin mount with a carbon tab (ProSci Tech) on it or in cryovials $(2 \mathrm{~mL})$. The samples on pin mounts were air-dried in a laminar flow cabinet for five days. Cryotubes with samples were frozen at $-80^{\circ} \mathrm{C}$ (Revco ULT390-5-D, Thermo Scientific) for $24 \mathrm{~h}$ and then freeze-dried (FD-8 Witeg Germany) for 24h. Dried samples were carefully placed on standard pin mounts with a carbon tab on top. Finally, all samples were sputter-coated with Mini Plasma Sputter Coater (gold: $0.1 \mathrm{~mm}$ ) and visualized and imaged using a Jeol JCM-6000 Versatile Benchtop SEM.

\section{In-Vitro Blastospore Formation From $N$. capsellae Multi-Celled Conidia}

Two drops $(20 \mu \mathrm{l})$ from multi-celled conidial suspension prepared as described before in the previous section on preparation of multi-celled conidial suspension, were placed on 10 standard glass microscope slides and incubated in a moist chamber. After a $24 \mathrm{~h}$ incubation period, $1 \%$ cotton blue in lactophenol was added to each drop, before examining under an Olympus BX5 microscope. From 5 random slides, a total of 50 fields (10 from each) were imaged with an Olympus DP71 digital photographic system.

\section{Morphological Analysis of In-Vitro Formed Blastospores (Single Spore/Cell) Types}

Two measurements (length and width) were taken from more than 400 spores using the software ImageJ 1.53a (Schneider et al., 2012) from digital images taken of two different single-celled blastospore types (micro-blastospores and meso-blastospores) produced from $N$. capsellae hyphae in pure cultures or multicelled macroconidia suspended in sterile distilled water. All the measurements for smaller bacteria-like spores (microblastospores) were taken from SEM images, and the larger 
yeast-like spore (meso-blastospore) measurements were taken from a combination of both SEM and LM images.

\section{Dimorphism In-Planta Host Genotypes}

Two genotypes from each of three major oilseed species were selected for in-planta studies. The six susceptible or resistant genotypes used were B. carinata (ATC94129P, highly resistant and UWA\#012, very susceptible), B. napus (Hyola 42, resistant and Trilogy, susceptible), and B. juncea (Dune, moderately resistant and Vardan, susceptible) (Gunasinghe et al., 2014).

\section{In-Planta Blastospore Formation From $N$. capsellae Hyphae}

Seeds of each genotype were sown in 48 cell seedling trays $(30 \mathrm{x}$ $34 \mathrm{~cm}$ ), four seeds per cell and four replicate cells per genotype. Ten days after sowing, plants were thinned to two per cell. Seedlings were grown in a controlled environment room $\left(15^{\circ} \mathrm{C}, 12 \mathrm{~h}\right.$ photoperiod, and Photosynthetic Photon Flux Density of $\left.580 \mu \mathrm{mol} \mathrm{m}^{-2} \mathrm{~s}^{-1}\right)$. Tenday-old cotyledons of each seedling were inoculated by depositing a single drop $(10 \mu \mathrm{l})$ of the mycelial suspension $\left(4 \times 10^{6} \mathrm{~mL}^{-1}\right)$, prepared as described earlier in the previous section on preparing of mycelial suspension, on each cotyledon lobe. The control was an identical tray of seedlings under the same conditions but inoculated with sterile distilled water. All plants were placed in clear polyethylene bags for $48 \mathrm{~h}$ to maintain high humidity to promote infection (Brun and Tribodet, 1991). Five cotyledons for each genotype, (4 inoculated and 1 control from each of the 5 cells) were randomly sampled for LM or SEM $48 \mathrm{~h}$ post-inoculation.

\section{In-Planta Blastospore Formation From N. capsellae Multi-Celled Conidia}

Collection of multi-celled macroconidia from diseased leaves and preparation of macroconidial suspension in sterile distilled water $\left(4 \times 10^{6} \mathrm{~mL}^{-1}\right)$ was done as described in the previous section on preparation of muiti-celled conidia. An experiment identical to mycelial inoculation studies was conducted, but by inoculating cotyledons with a $10 \mu \mathrm{m}$ multi-celled conidial suspension rather than mycelial suspension. After $48 \mathrm{~h}$ post-incubation, two sets of five cotyledons (four inoculated and one control) were collected separately for LM and SEM.

\section{Sample Preparation for Microscopy and Morphological Analysis of Blastospores (Single Spore/Cell Types) Produced In-Planta}

For LM studies, collected cotyledons were decolourized with acetic acid: ethanol: water (2:2:1) solution and stained with $1 \%$ cotton blue in lactophenol for $40 \mathrm{sec}$ to prepare whole wet mounts (Gunasinghe et al., 2016c). Four inoculated and one uninoculated cotyledons were examined using an Olympus (BX51) microscope, where 25 random images from each inoculated site (50 from a cotyledon and a total of $50 \times 4=$ 200 for each genotype) were captured using an Olympus DP71 digital photographic system.

For SEM studies, cotyledon samples were fixed in $2.5 \%$ glutaraldehyde and cut into $4 \times 4 \mathrm{~mm}$ pieces and transferred into glass vials with fresh $2.5 \%$ glutaraldehyde. Samples were then prepared for SEM using a BioWave microwave processor fitted with a PELCO coldspot (Gunasinghe et al., 2016c). Prepared samples were mounted on standard aluminium pin mounts with carbon tabs (ProSciTech), sputter-coated with $5 \mathrm{~nm}$ carbon, $3 \mathrm{~nm}$ platinum, and surface imaged with a field emission SEM (Zeiss Supra $55 \mathrm{VP}$ ). Twenty-five random images were taken from each of the inoculated areas (50 from a cotyledon and a total of $50 \times 4=200$ for each genotype).

Different blastospore types formed from $N$. capsellae multicelled macroconidia or hyphal fragments were measured using the software ImageJ 1.53a. Two measurements from more than 400 micro-blastospores (bacteria-like single-celled spores) from SEM images and meso-blastospores (Yeast-like single-celled spores) from a combination of both SEM and LM images were taken.

\section{Molecular Identification}

Confirmation of the identity of the two observed morphologically different phases (Hyphae and single-celled blastospores) was undertaken by sequencing the internal transcribed spacer region (ITS1, 5.8S, and ITS4) of the rDNA operon, and comparing sequence data with available sequence information data for $N$. capsellae isolates in GenBank. Areal hyphae obtained from a pure mycelial colony and single-celled blastospores collected from a young bacterial-like colony consisted only of blastospores have been used to extract DNA. To obtain the hyphal phase, five Petri Plates containing $15 \mathrm{~mL}$ NDY were inoculated with a mycelial plug taken from a threeweek-old culture of the isolate UWA Wlj-3 on MEA plates at the mycelial phase. After 20 to 30 days of incubation at $23^{\circ} \mathrm{C}$, plates were examined to select a plate with mycelial growth and no blastospores. Aerial mycelium (hyphae) from selected NDY cultures was harvested and placed in a sterile Eppendorf tube. Streak plates of YEPD (in duplicate) from the same isolate: UWA Wlj-3 were prepared from the same mycelial colony on MEA to obtain yeast phase (single cells). YEDP was used to induce the unicellular phase of the pathogen (Zhu et al., 2017). After two days of incubation at $23^{\circ} \mathrm{C}$ in dark, cells from the growing yeastlike colonies were aseptically transferred into a sterile Eppendorf tube.

\section{Extraction of Genomic DNA, PCR, and Sequencing} Genomic DNA was extracted using the ISOLATE II Genomic DNA Kit (Bioline (Aust) Pty Ltd) with some modifications to the standard protocol. All samples with mycelia or single cells (yeast phase) were washed with $400 \mu$ l of TE buffer in an Eppendorf tube, pelleted by centrifugation $(13,000 \mathrm{rpm}, 5 \mathrm{~min})$ in a microfuge ${ }^{\circledR} 18$ (Beckman Coulter ${ }^{\mathrm{TM}}$ ) and the supernatant was discarded. Lysis buffer $(200 \mu \mathrm{l})$ and two metal beads were added to each of the sample and homogenized with the tissue homogenizer (FastPrep-24TM 5G Homogenizer - MP Biomedicals) for 6 seconds. Genomic DNA extraction in the homogenized samples was carried out using the ISOLATE II Genomic DNA Kit according to manufacturer instructions. All DNA samples were stored at $4^{\circ} \mathrm{C}$ after evaluating the quality and 
concentration of DNA extracted using a DeNovix: DS-11 FX Spectrophotometer/Fluorometer.

Part of the nuclear rRNA operon was amplified with primers ITS1 (5'TTT CCG TAG GTG AAC CTG C3') and ITS4 (5'TCC TCC GCT TAT TGA TAT GC3') using the polymerase chain reaction (PCR) (Gunasinghe et al., 2016a). Spacer I, between the $18 \mathrm{~S}$ and 5.8S rRNA gene, was amplified using the 5' primer ITS1, and spacer II, between $5.8 \mathrm{~S}$ and $28 \mathrm{~S}$ of the rRNA gene, was amplified with the 3' primer ITS4. PCR reactions were carried out with 50ng genomic DNA in MyTaq Red mix (Bioline (Aust) Pty Ltd). PCR conditions were: initial denaturation step at $94^{\circ} \mathrm{C}$ for 2 minutes, followed by 35 cycles of 1 minute at $94^{\circ} \mathrm{C}$, annealing at $55^{\circ} \mathrm{C}$ and extension for 1.5 minutes at $72^{\circ} \mathrm{C}$ and a final elongation step of $72^{\circ} \mathrm{C}$ for 2 min (Gunasinghe et al., 2016a). PCR products were separated and visualized by gel electrophoresis at $84 \mathrm{~V}$ for 45 minutes on a $1 \%(\mathrm{w} / \mathrm{v})$ agarose gel and products of $500 \mathrm{bp}(20 \mu \mathrm{l}$ of each) were sequenced by Macrogen Inc. (Korea).

\section{RESULTS AND DISCUSSION}

Observations confirmed the morphogenic plasticity of $N$. capsellae. The species changed its morphology from septate hyphal growth to budding yeast form or vice-versa depending on external conditions. The morphological transformation (hyphae-to-yeast) of $N$. capsellae resulted in two common single-celled blastospore (blastoconidia) types distinguished based on gross appearance: The first, predominantly elliptical and comparatively large single-celled meso-blastospores that resembled yeast cells where average dimensions were $4.8 \mathrm{x}$ $2.7 \mu \mathrm{m}$ (Table $\mathbf{1}$ and Figure 1A) and the second, single-celled micro-blastospores (average dimensions of 1.9 X $0.9 \mu \mathrm{m}$ ) that resembled rod-shaped bacterial cells (Table 1 and Figure 1B) and comparatively large, spherical to cylindrical arthrospores (arthroconidia) (Figure 1C). The formation of blastospores (Odds and Kerridge, 1985; Gauthier, 2015; Lin et al., 2015) and arthrospores (Barrera and Szaniszlo, 1985) are important aspects of fungal morphogenesis in many dimorphic or polymorphic fungal species, including Ascomycetes. Blastospores are asexually produced single-celled spores that can increase in number rapidly through repeated budding (Odds and; Kerridge, 1985; Mehrabi et al., 2006; Lin et al., 2015), while arthrospores are formed by segmentation and subsequent fragmentation of existing hyphae (Barrera and Szaniszlo, 1985).

This morphological transition in $N$. capsellae has not been previously recognized. To eliminate the potential for contamination being the source of the newly described structures, the identity of the structures was confirmed by PCR amplification and sequencing of the ITS1 and ITS4 regions of nuclear ribosomal DNA of blastospores taken from a yeast-like colony (GenBank Acc. No. MZ149251) and hyphae from a pure mycelial colony (GenBank Acc. No. MW898135). The BLAST results for both samples were $99 \%$ match to N. capsellae.

\section{In-Vitro Morphogenesis Pure Cultures on Growth Media}

The formation of single-celled spores (blastospores and arthrospores) produced prominent changes in colony morphology (Figures 2 and 3). Morphological transformation from hyphae-to-yeast or yeast-to-hyphae was observed on all 5 tested media, although some different media favoured the formation of yeast and the other the formation of mycelial phase. Transferring hyphae to a fresh medium (subculturing) initiate yeast-like colonies on some media demonstrating hyphae-to-yeast transformation. Generally, on commonly used media like PDA or NDY, and WA, the mycelial phase dominated with an infrequent, short, initial yeast-like phase immediately after subculturing. When yeast-like growth was observed initially (Figures 2A, B), yeast-to-hyphae transition was initiated in colonies anytime within two-three weeks (Figures 2C, D). The hyphae-to-yeast transformation was also observed in mycelial colonies older than one month (Figure 3). At the initial growth stage on some media such as NDY, PDA, and WA, the yeast phase was present but visible only under the microscope and the proportion of yeast to mycelia and the time taken for the yeastto-hyphae transformation differed across the media tested.

Subculturing and the method of inoculation influenced the morphological transformation of the fungus. Placing N. capsellae hyphal fragments onto a new growth medium promoted the initial formation of creamy white-to-tan-coloured colonies dominated by single-celled blastospores (Figures 2A, B). Similar growth behaviour on agar media by dimorphic pathogens has been observed. Initially formed yeast-like colonies of Candida citri switched to mycelial growth after prolonged incubation (Sipiczki, 2011). Odds and Kerridge (1985) claim that the C. albicans blastospore-dominating yeast phase was easy to obtain and maintain on artificial media, while the pure mycelial phase was difficult to attain as it is only a transient form.

Of the two inoculation methods tested, streaking favoured the formation of the yeast phase. Hyphal growth with or without initial yeast-like growth was observable on PDA, NDY, and V8 juice agar when inoculated with an agar plug (Figures 4A, B, F).

TABLE 1 | Spore dimensions ( $\mu \mathrm{m})$ of two types of blastospores: meso-blastospores and micro-blastospores.

\begin{tabular}{|c|c|c|c|c|}
\hline & Meso blastospore in-planta & Meso blastospore in-vitro & Micro blastospore in-planta & Micro blastospore in-vitro \\
\hline Average Width & $2.9 \pm 0.82$ & $2.7 \pm 0.64$ & $0.65 \pm 0.15$ & $0.9 \pm 0.34$ \\
\hline Range & $0.9-6.6$ & $1.0-4.9$ & $0.2-1.0$ & $0.3-2.0$ \\
\hline Average Length & $3.4 \pm 0.95$ & $4.8 \pm 1.24$ & $1.1 \pm 0.13$ & $1.9 \pm 0.44$ \\
\hline Range & $0.9-7.1$ & $2.3-9.2$ & $0.3-2.5$ & $0.7-3.4$ \\
\hline
\end{tabular}

Values are the mean of more than 400 cells from each morphotype measured in-vitro and in-planta. 

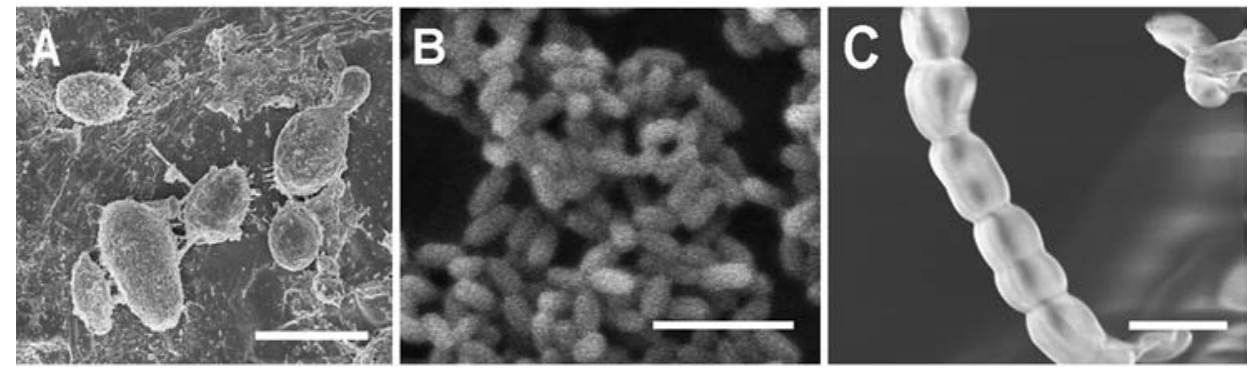

FIGURE 1 Scanning electron micrographs of single-celled spore types with different morphologies produced by Neopseudocercosporella capsellae during morphological transformation from hyphae-to-yeast. (A) Unicellular meso-blastospores. (B) Unicellular micro-blastospores. (C) Arthrospore chain. Scale bars = 5 4 m.

Except for WA, yeast-like colonies appeared on streak plates of all media within $24 \mathrm{~h}$ of inoculation (Figures 4C, D). On WA, yeast-like colonies, hyphal growth, or both were observed during the initial growth stage depending on the inoculation method used (Figure 4E). The appearance of initial yeast-like colonies immediately after subculturing was fast, within overnight incubation (Figures 4C, D), while it took at least 10-14 days for hyphal growth to occur when the initial yeast growth was absent (Figures 4E, F).

The co-occurrence of cells with different morphologies varying from single-celled blastospore types to true hyphae in a single colony was observed in N. capsellae colonies (Figure 5). However, the dominating morphotype and the architecture of the colonies seem to depend on several factors, such as isolate,
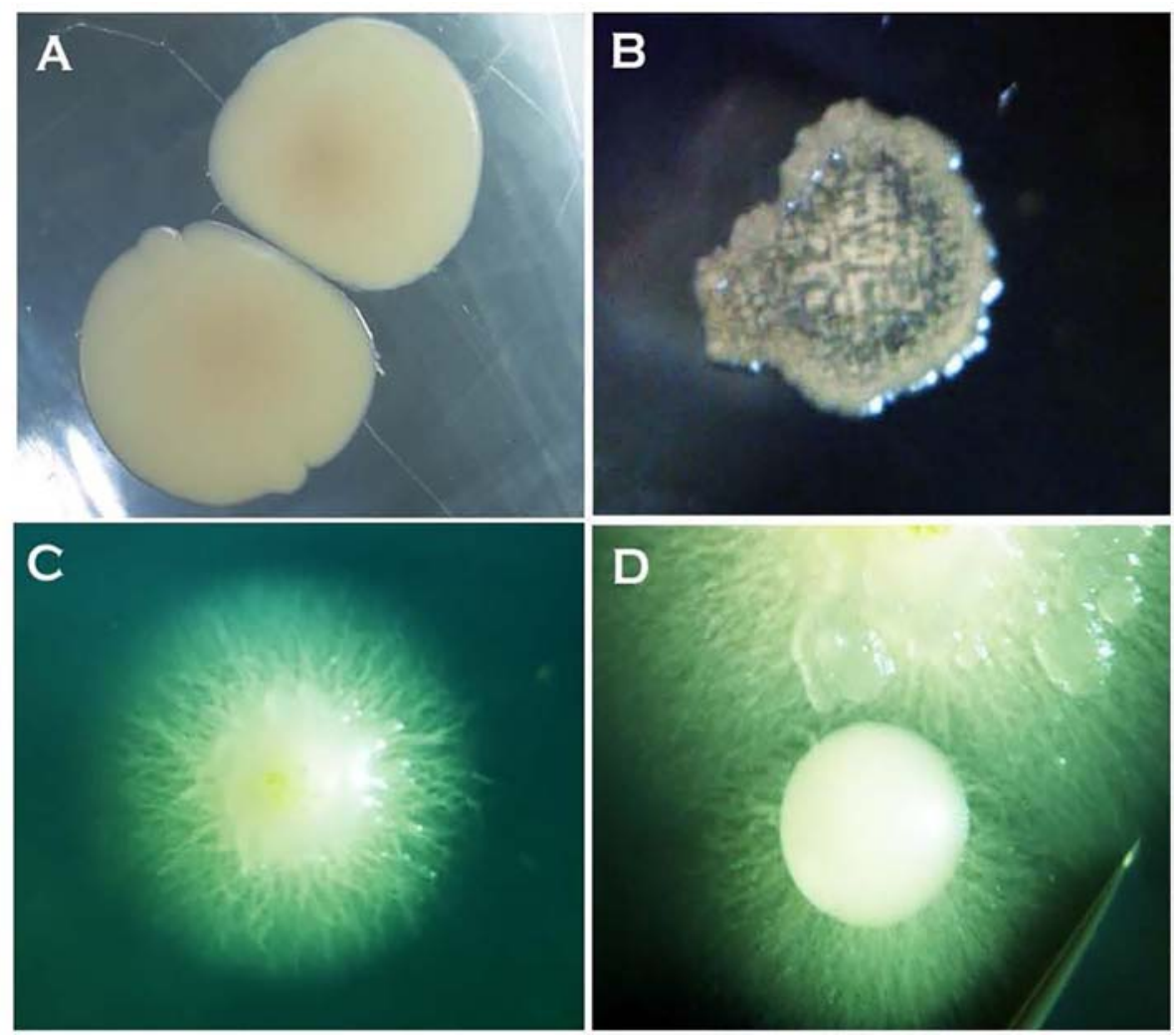

FIGURE 2 | Two-day-old bacteria-like colonies of Neopseudocercosporella capsellae consisting of single-celled blastopores appeared after streak-inoculation using hyphal fragments from a pure hyphal colony. (A) Isolate UWA Wlj-3 on NDY and (B) isolate UWA WIra-7 on PDA. (C) and (D) Ten-day-old colonies of isolate UWA Wlj-3 on PDA where hyphae initiation is evident at the periphery at the transition stage from a bacterial-like initial stage. 

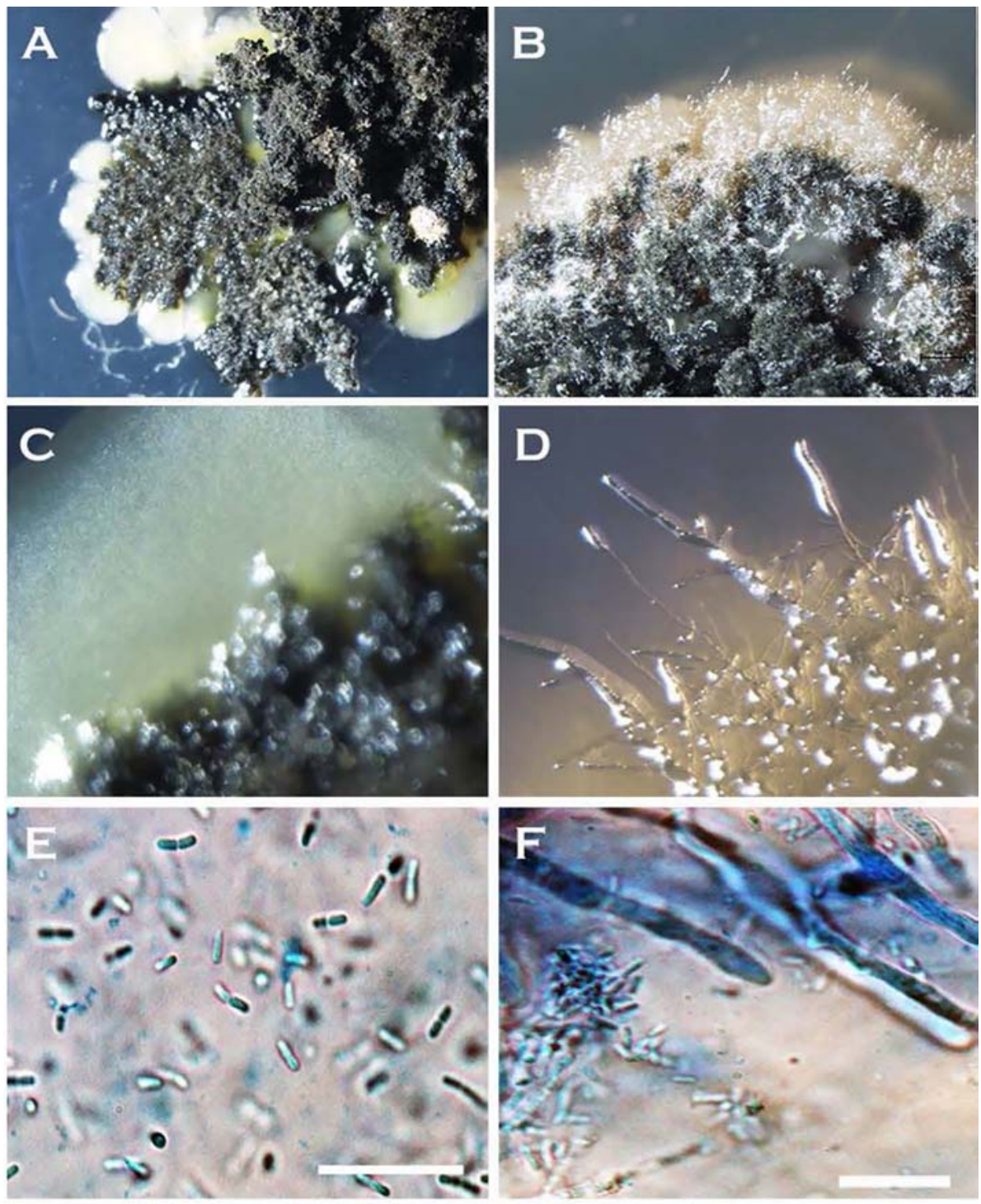

FIGURE 3 | Morphological transformation (hyphae-to-yeast) of Neopseudocercosporella capsellae cultures on growth media where blastospores are seen as creamy white to tan masses at the edges of colonies (A-D). Colonies at the time of hyphae to yeast transformation, (A) seven week old colony of isolate UWA Wli-3 on NDY, and (B) five week old colony of isolate UWA WIra-7 on PDA. (C) Edge of the UWA Wli-3 colony, and (D) edge of UWA Wira-7 colony, where hyphae-toyeast transformation occurred. (E) Blastospores from UWA Wij-3 colony and (F) hyphae from UWA Wlra-7 colony, both stained with $1 \%$ cotton blue in lactophenol and as seen under the light microscope. Scale bar $=5 \mu \mathrm{m}$.

method of inoculation, and type of the growth medium and changed over time with the age of the colony (Figures 2 and 3 ). The formation of mixed colonies with different cell morphologies has been reported in other dimorphic pathogens such as Cryptococcus (Levy et al., 2012; Lin et al., 2015) and Candida sp. (Odds and Kerridge, 1985; Sipiczki, 2011). Cryptococcus produces colonies with different morphologies, where yeast cells (blastospores) predominate in the colony centre and hyphae dominate at the periphery (Lin et al., 2015). Obtaining a colony consist of single-cell morphology was a difficult task for C. albicans on artificial culture media because of the co-existence of blastospores, hyphae, and pseudohyphae (Odds and Kerridge, 1985). Such colonies, the architecture of the colony, degree of morphological heterogeneity, and the proportion of each cell morphology of otherwise genetically identical cells, are a result of differential gene expression among cells (Levy et al., 2012) as influenced by one or more of several factors, such as gradient of signalling molecules created by the varying microenvironments across the growth medium and/or factors like the age or cellcycle stage (Lin et al., 2015).

Apart from much larger colonies at $37^{\circ} \mathrm{C}$, the same growth patterns were observed at both temperatures $\left(23^{\circ} \mathrm{C}\right.$ and $\left.37^{\circ} \mathrm{C}\right)$. 

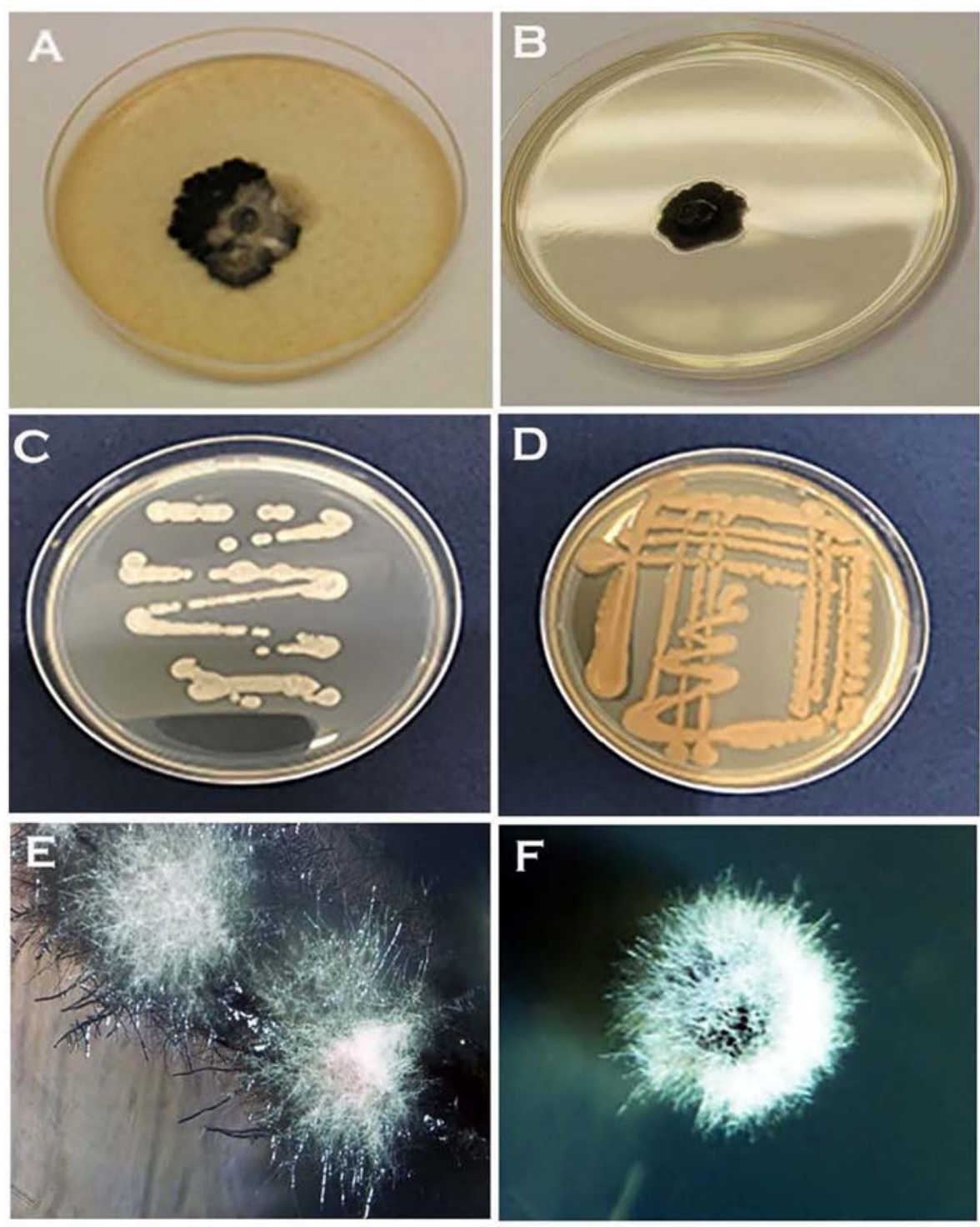

FIGURE 4 | Different colony morphologies of Neopseudocercosporella capsellae isolate UWA Wli-3 grown on three different growth media, and with two different subculturing methods using a hyphal colony on a single growth medium. (A) Seven week old colonies on V8 juice agar and (B) PDA, inoculated with an agar plug. Four-day-old streak plate on (C) PDA and (D) V8 juice agar. (E) Four-week-old hyphal colonies on WA streak plate. (F) Three-week-old hyphal colony on NDY inoculated with an agar plug.

Therefore, these in-vitro studies at two temperatures suggest that N. capsellae morphogenesis is not induced solely by temperature as seen in thermally dimorphic human fungal pathogens (Dukik et al., 2017), but by more complex external and internal factors, including the growth medium.

\section{Multi-Celled Macroconidia in Sterile Distilled Water}

Multi-celled macroconidia produced both micro-blastospores and meso-blastospores or arthrospores in-vitro within a $24 \mathrm{~h}$ incubation period. All three spore types were stained with cotton blue and observable under LM among the multi-celled macroconidia when suspended in sterile distilled water (Figure 6).
However, not all multi-celled conidia produced single-celled blastospores, as some germinated by producing single or multiple germ tubes.

\section{In-Planta Morphogenesis}

Multi-celled macroconidia or hyphal fragments newly introduced onto host tissue (cotyledons) formed single-celled blastospores or arthrospores displaying the same trend of morphological transition that occurred in-vitro. All singlecelled spore types similar to the spore types produced in-vitro (meso and micro-blastospores and arthrospores) were evident on cotyledons inoculated with multi-celled macroconidia 


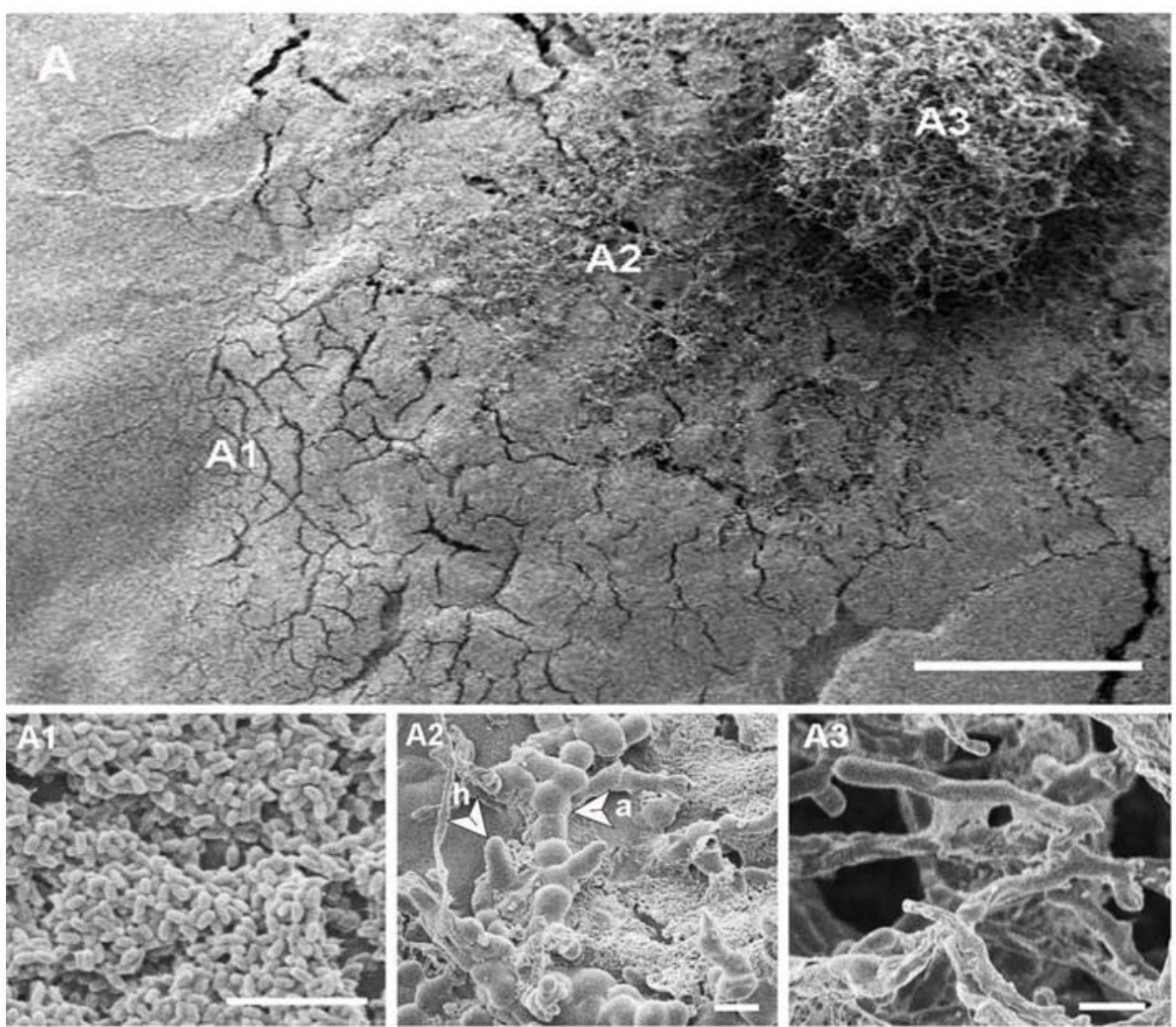

FIGURE 5 | (A) Scanning electron micrograph of a three-week-old heterogeneous Neopseudocercosporella capsellae isolate UWA Wlj-3 colony on PDA, showing cell types with different morphologies at different places in the culture, scale bar $=500 \mu m$. (A1) Blastospores (yeast cells) dominating at the periphery of the colony. (A2) Middle area of colony showing a mixture of blastospores, arthrospores (a) and hyphae (h). (A3) Centre of the colony dominated by true hyphae. Scale bars $=10 \mu \mathrm{m}$.

suspensions (Table $\mathbf{1}$ and Figures 7A, B, E, F) or mycelial fragments (Figures 7C, D) within 48 h post-inoculation and this was consistent across all six test genotypes belonging to three different host species. However, germinated multi-celled macroconidia with single or multiple germ tubes were also common. Initial observations were that the amount of germinating multi-celled macroconidia or each morphologically different single-celled blastospore type could vary depending on the host, such as susceptible and resistant host species. After landing on the host tissue, the formation of a single-celled blastospore (yeast phase) on the host surface just before invasion has been observed for several dimorphic plant pathogens (Ingold, 1995; Ruiz-Herrera et al., 1995; Vollmeister et al., 2012; Cissé et al., 2013). Asexually produced diploid, multi-celled pycnidiospores of Zymoseptoria tritici, a dimorphic wheat pathogen causing Septoria tritici blotch (Palmer and Skinner, 2002; Mehrabi et al., 2006) or teliospores of Ustilago maydis, a maize pathogen causing smut disease (RuizHerrera et al., 1995; Vollmeister et al., 2012), establish a short yeastlike phase on the leaf surface by producing blastospores before host invasion in the filamentous form. In Taphrina deformans, the cause of leaf curl disease of peach and nectarine, ascospores discharged from curled leaves produce single-celled blastospores, that overwinter and then switch back to the infectious filamentous form to invade the host (Rodrigues and Fonseca, 2003; Tavares et al., 2004; Cissé et al., 2013). This morphological transition from multi-celled conidia or hyphae-to-yeast and yeast-to-hyphae plays unique species-specific roles in virulence (Mehrabi et al., 2006; Gauthier, 2015; Lin et al., 2015). For instance, yeast cells of T. deformans function as an overwintering dormant spore (Cissé et al., 2013), while dissemination is the key role of yeast cells produced by Ophiostoma ulmi (Lin et al., 2015).

\section{Blastospore (Blastoconidia) Formation}

In $N$. capsellae, blastospores are produced during hyphae-toyeast transition from multi septate hyphae (Figure 3) or by asexually produced multi-celled macroconidia (Figures 6 and 7). Although there can be a variety of different morphologies observed, the formation of blastospores involves three steps of bud emergence, bud growth, and spore/conidia separation. The sites at which blastospores are produced during hyphae-to-yeast transformation could be limited and for C. albicans these hyphal sites are adjacent and posterior to septa (Odds and Kerridge, 1985). Similarly, in N. capsellae yeast-like meso-blastospore formation occurred at the septa of hyphae (Figures 8A, B) or 

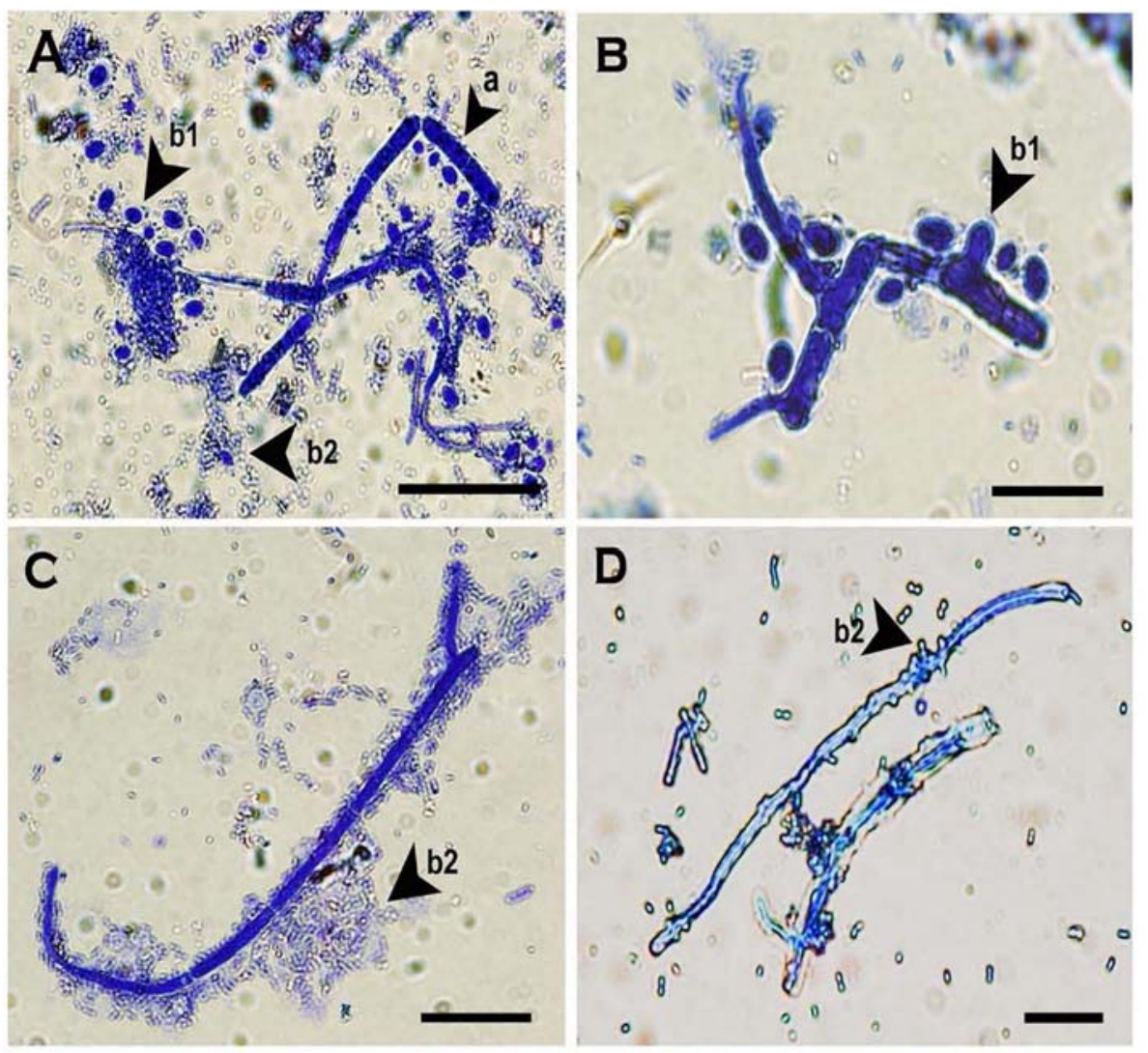

FIGURE 6 | Two morphologies of blastospores and arthrospores formed from Neopseudocercosporella capsellae multi-celled macroconidia suspended in sterile distilled water 24h post-inoculation. (A) Multi-celled macroconidia with meso-blastopores (b1), micro-blastospores (b2) and an arthrospore (a).

(B) Multi-celled macroconidium producing meso-blastospores (b1) (arrow shows a meso-blastospore bud raised adjacent to the septa). (C) Multi-celled macroconidium with micro- blastospores (b2). (D) Micro-blastospore (b2) formed from multi-celled macroconidia (arrow shows buds of micro-blastospores).

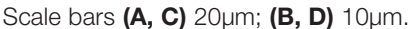

the tip (Figure 8B). However, micro-blastospore formation from hyphae was random and occurred in comparatively large numbers (Figures 8C, D).

\section{Arthrospore (Arthroconidia) Formation}

The formation of single-celled arthrospores from existing hyphae has long been observed during fungal morphogenesis in certain fungal species (Miyazi and Nishimura, 1971; Bibel et al., 1977; Emyanitoff and Hashimoto, 1979; Cartwright et al., 2014). These single-celled spores are produced in extensive numbers to enhance the pathogen's reproductive potential and, therefore, the primary function of arthrospore is reproduction rather than survival between seasons. However, arthrospores can also be the principal means of dissemination in certain pathogenic fungi (Barrera and Szaniszlo, 1985). Arthroconidia formation and morphogenesis in dimorphic human fungal pathogens can be stimulated by several types of environmental stress conditions related to growth medium composition, carbon dioxide tension, and increased temperatures (Rippon and Scherr, 1959; King and Jong, 1976; Bibel et al., 1977; Emyanitoff and Hashimoto, 1979). Initiation of arthro sporogenisis, the age of conidia formation, and the number of conidia formed are all highly species-specific (Barrera and Szaniszlo, 1985).

Arthro sporogenesis of $N$. capsellae was observed in-vitro from multi-celled hyphae on different artificial media (Figure 9) or multicelled macroconidia (Figure 10). This is the first report showing arthrospores from $N$. capsellae, although the cleavage of multi-celled macroconidia on cotyledons to produce single cylindrical entities by this pathogen has been reported earlier by Gunasinghe et al. (2016d). Two different morphologies commonly observed for $N$. capsellae arthrospores were cylindrical (Figures 9A, B) or spherical (Figures 9C, E). Initial observations are that the size of the arthrospores and the proportion of each morphology in-vitro vary depending on the growth conditions. This is not unusual as other dimorphic fungal species can produce a range of arthroconidia that differ in size and/or shape and the dominating type is determined by the substrate (King and Jong, 1976; Allermann et al., 1978; Kier et al., 1980; Barrera and Szaniszlo, 1985).

The development and release of arthroconidia appear to vary depending on the fungal species (Barrera and Szaniszlo, 1985). In both: Mucor rouxii and Tricophyton mentagrophytes, arthroconidia develop inside the hyphae as cylindrical conidial 

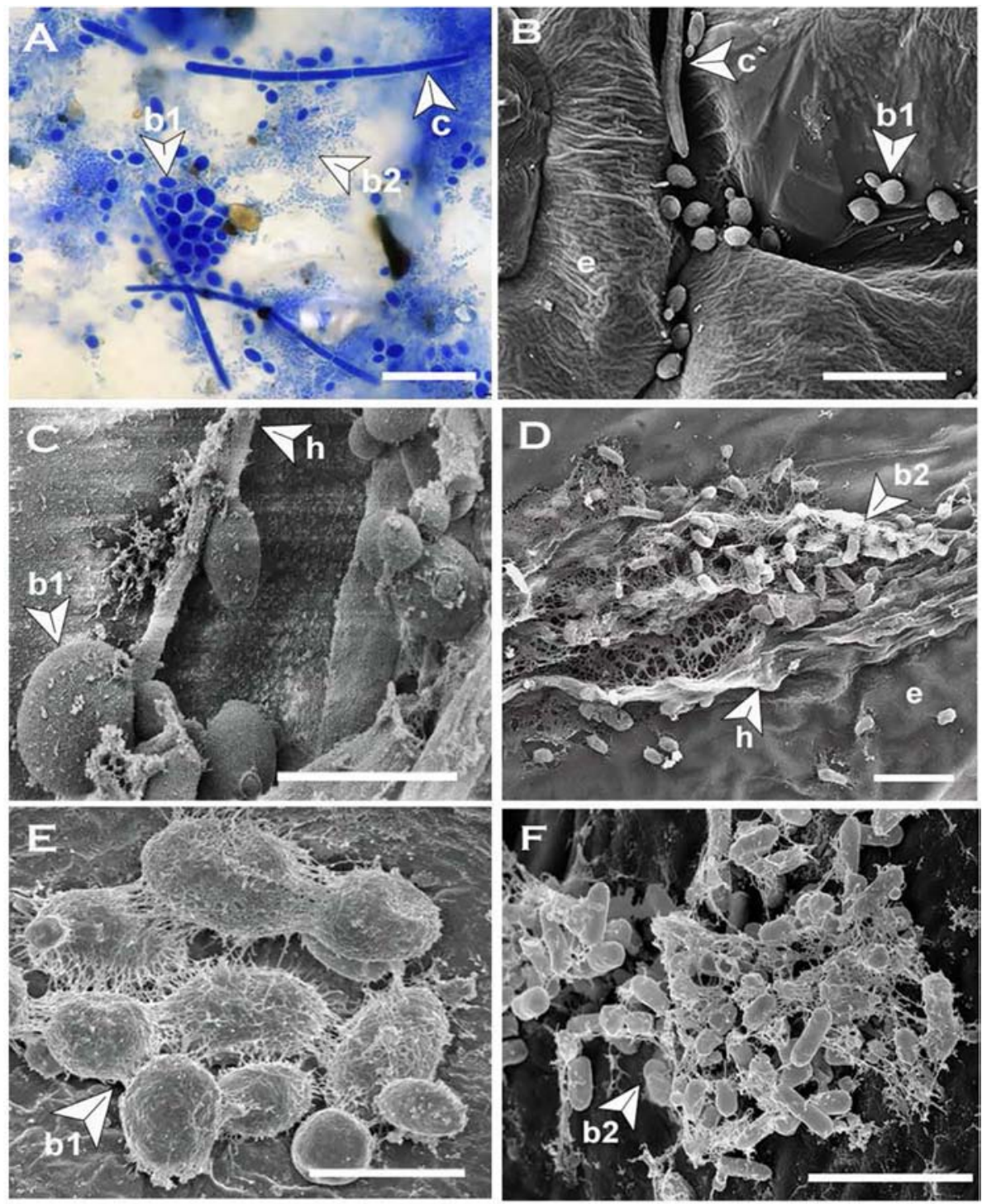

FIGURE 7 | Blastospores produced by Neopseudocercosporella capsellae on cotyledons of the host Brassica juncea or B. napus. (A) Multi-celled macroconidia (c), meso-blastospores (b1) and micro-blastospores (b2) on a cotyledon surface 48h post-inoculation with a multi-celled macroconidial suspension (cotyledons were decolorized by immersing in acetic acid:ethanol:water $(2: 2: 1)$ solution at $25^{\circ} \mathrm{C}$ for $3-4$ days before visualization under the light microscope (scale bar $\left.=20 \mu \mathrm{m}\right)$.

(B) Cotyledon surface inoculated with a multi-celled macroconidial suspension showing multi-celled macroconidia (c), meso-blastospores (b1), and epidermal cells (e)

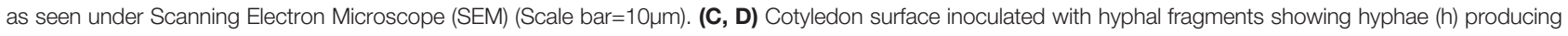
meso-blastospores (C) (Scale bar=5 $\mathrm{m}$ ) and micro-blastospores (D) (Scale bar=1 $\mu \mathrm{m})$ as seen under SEM. (E, F) Morphology of meso-blastospores (E) (Scale bar $=5 \mu \mathrm{m})$ and micro-blastospores $\mathbf{( F )}($ Scale bar=1 $\mu \mathrm{m})$ produced in planta as seen under SEM.

chains enveloped by the original hyphal cell wall but then change their morphology to spherical just before dehiscence (Takeo and Nishiura, 1974; King and Jong, 1976). Separation of the conidia could occur by autolysis of inter-septal material in the original hyphal wall that helps the adhesion of neighbouring septal walls of conidial chains or by dehiscence of the original hyphal wall (Barrera and Szaniszlo, 1985). The arthroconidia of Antromycopsis brousonnetiae developed a secondary cell wall inside the hyphae and the separation of conidia is by centripetal dehiscence of the original hyphal wall (Moore, 1977).
The frequently observed release mechanism for N. capsellae arthrospores produced in-vitro was dehiscence of original hyphae. Transverse dehiscence at the septa was more common (Figures 9C-E) than centripetal dehiscence (Figure 9F). However, the release of cylindrical arthrospores by autolysis of the original hyphal wall also occurred when arthrospores were produced from multi-celled macroconidia (Figure 10). There is evidence that arthrospores are a superior asexual spore type providing enhanced dissemination and better establishment on the host tissue by protecting cells from host lytic enzymes 


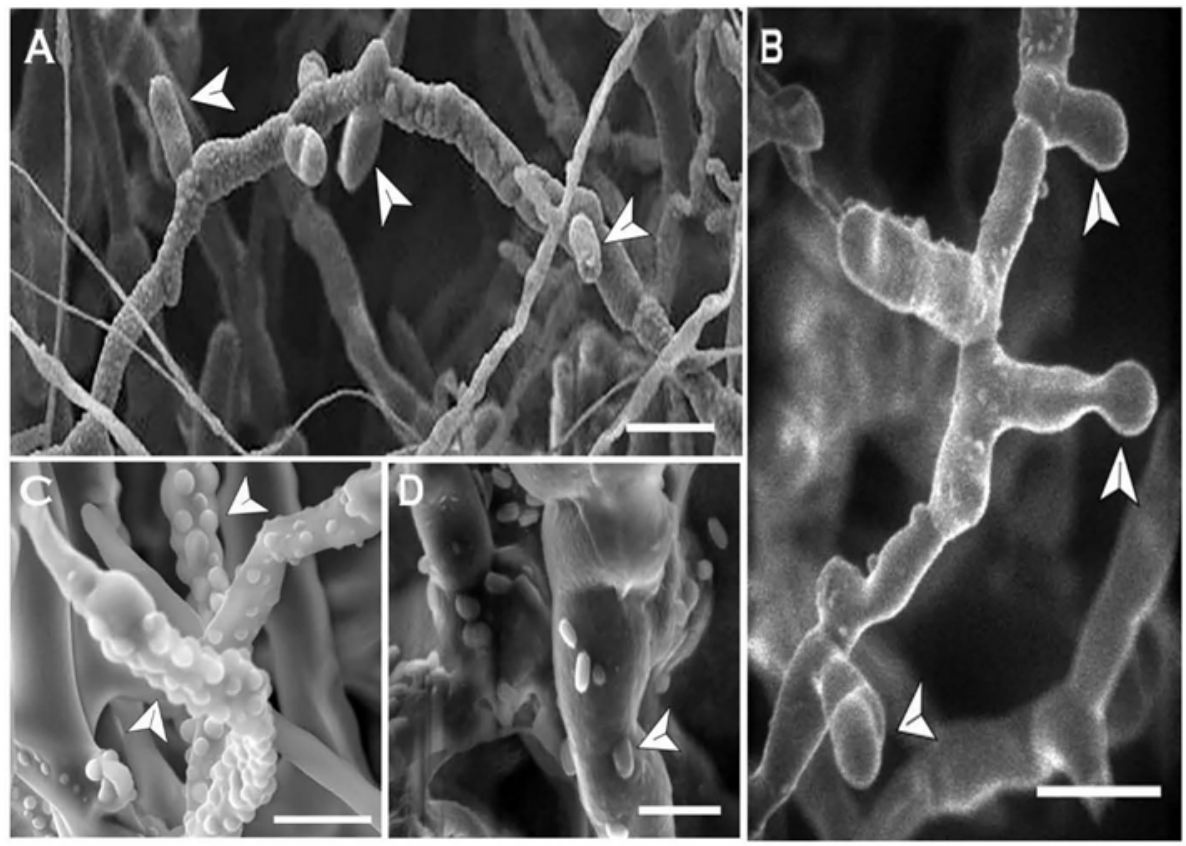

FIGURE 8 | In-vitro blastospore formation by Neopseudocercosporella capsellae hyphae as seen under the scanning electron microscope. Old septate hyphae producing meso-blastospores (arrows) at the septa (A) and the tip (B) at the transition stage (Scale bars =10 $\mathbf{M m})$. (C) Young hyphae showing buds for microblastospores (Scale bar $=5 \mu \mathrm{m}$ ). (D) Old hyphae with micro-blastospore buds and single-celled micro-blastospores (arrows) separated from the original hyphae (Scale bar $=2 \mu \mathrm{m})$.

(Duran et al., 1973), increasing antibiotic production (Nash and Huber, 1971; Queener and Ellis, 1975), and by promoting surface adherence (Kurakado et al., 2020).

\section{Morphological Plasticity, Pathogen Biology, and Disease Epidemiology}

Although white leaf spot has been a damaging disease on Brassicaceae, there is relatively little information on the pathogen's biology and disease epidemiology (Gunasinghe et al., 2020). It has been suggested that the pathogen is under-reported as the causative agent, because of the difficulties in isolation related to the slow growth on artificial media (Gunasinghe et al., 2020). As demonstrated by this study the initial growth of $N$. capsellae on artificial media can initially mimic bacterial/yeast colonies (Figures 2A, B and Figures 4C, D). This ability to form strikingly different colony morphology following in-vitro morphological transition creates difficulties in identification based on colony morphology which also potentially leads to under-reporting.

Morphological transformation in fungi plays critical roles in survival between seasons, dissemination, and host invasion and therefore, in virulence (Lin et al., 2015). Dimorphic or polymorphic fungi achieve this through the morphological transformation into single-celled spore types with different morphologies (blastospore or arthrospores) and/or varied physiologies (Odds and Kerridge, 1985) having altered tolerance to certain host physiological conditions making them more robust on hosts (Lin et al., 2015). In the absence of the teleomorph (sexual stage) $N$. capsellae infection cycle is not fully understood (Gunasinghe et al., 2020), as splash-dispersed multicelled macroconidia are unlikely to be dispersed by wind (Fitt et al., 1992). The morphological transition on host leaves may provide a superior spore that can be efficiently disseminated through wind facilitating disease initiation and spread in the localities like North America, Asia, and Australia where the sexual stage and, therefore, ascospores are thought to be absent.

In the literature, polymorphism is defined as the ability of a fungus to take more than two different morphological forms (Mayer et al., 2013). Candida albicans provides a classic example for polymorphic pathogenic fungi, where it can form biofilms, different morphotypes for the single-celled blastospores (yeast phase), hyphae, and pseudo-hyphae (Odds and Kerridge, 1985; Kurakado et al., 2020). Formation of biofilm at the interface of yeast-to-hyphae transition was also observed for $N$. capsellae in this study. It is known that biofilm development and morphogenesis are interconnected phenomena controlled by the same set of genes for a given species (Lin et al., 2015; Kurakado et al., 2020). Further studies are recommended not only to answer the question of whether $N$. capsellae is dimorphic or polymorphic but also to define the decisive role/s of each morphotype produced understanding its morphogenesis.

\section{CONCLUSION}

N. capsellae has the morphological plasticity to produce different morphologies in response to various environmental/external 

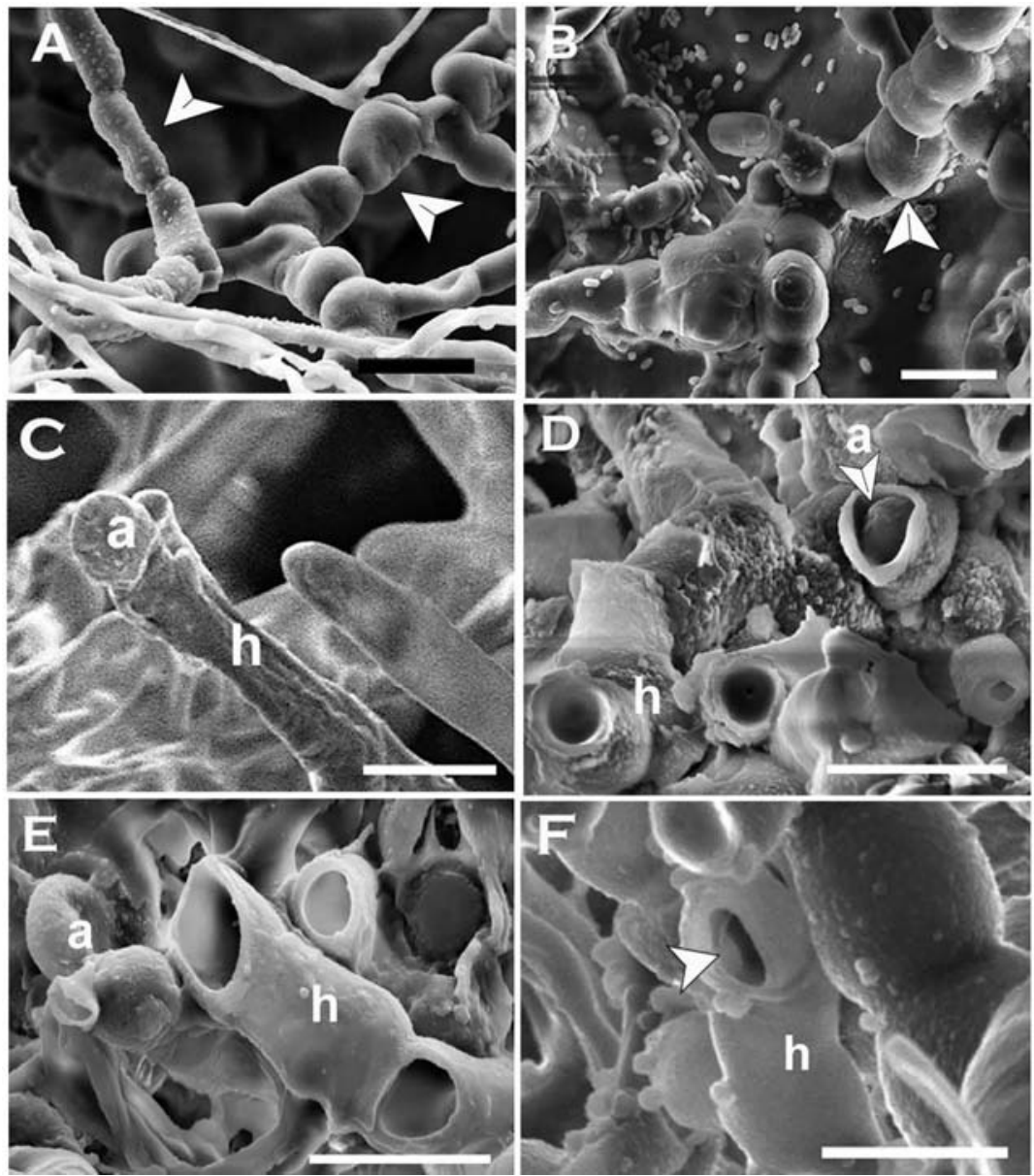

FIGURE 9 | Formation and release of arthrospores (arthroconidia) produced in-vitro from Neopseudocercosporella capsellae hyphae as seen under the scanning electron microscope. (A, B) Series of delicately attached arthrospores (arrows) produced by 7 week old colonies of isolate UWA WIj-3 on NDY (A) and PDA (B). The arthrospores break off and disseminate when disturbed (Scale bars $=5 \mu \mathrm{m})$. (C, D) Releasing spherical arthrospore (a) after transverse dehiscence of the hyphae (h) at the septa. (D, F) Hyphal cell walls after releasing arthrospores by dehiscence along the septa (C) or centripetal dehiscence (D) (Scale bars $=5 \mu \mathrm{m})$.
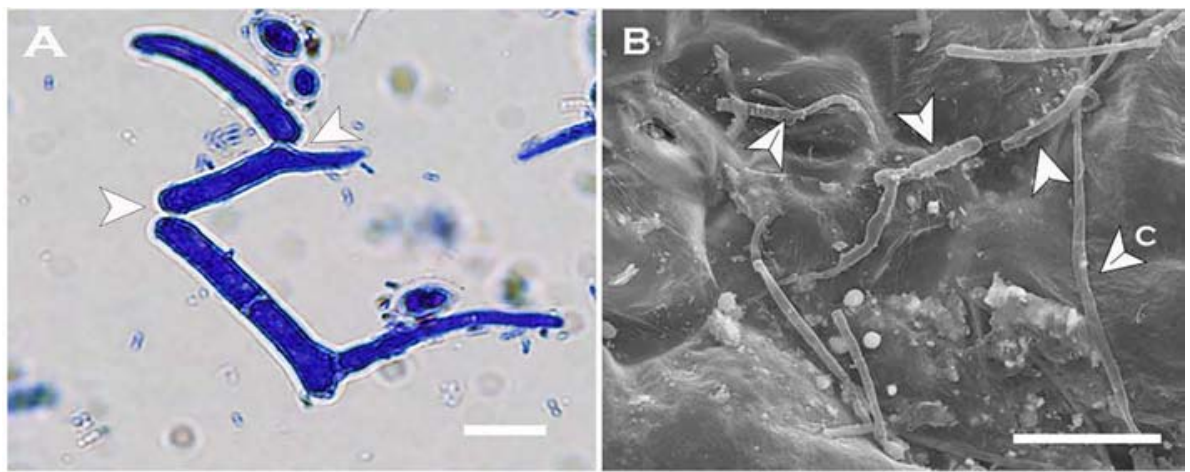

FIGURE 10 | Arthrospores produced by Neopseudocercosporella capsellae multi-celled macroconidia on the host. (A) Cylindrical arthrospore formation by disintegration of original macroconidia cell walls at septa (arrows) on the cotyledon surface as seen under the light microscope. (B) Scanning electron micrograph of multi-celled macroconidia (c) and germinating three arthrospores as single-celled spores by producing a single germ tube each (arrows) on the cotyledon. Scale bars $=10 \mu \mathrm{m}$. 
stimuli. During its morphogenesis, dikaryotic mycelium or asexually produced multi-celled macroconidia (2n) on leaf lesions in their parasitic phase initiate a single-celled yeast phase through the production of at least three types of morphologically distinguishable single-celled spore types. Multicelled macroconidia on the host surface develop in three possible ways 1) they separate from the septa to produce multiple arthrospores that germinate as single entities, 2) they produce blastospores that increase in number rapidly by budding, and 3) they germinate as typical conidia by producing single or multiple germ tubes. This morphological plasticity of $N$. capsellae can be considered a cost-efficient strategy to provide a more resilient form of spores on the host enhancing inoculum potential and dissemination, both contributing to the pathogen's virulence. A systematic study is recommended to fully understand N. capsellae multifaceted life cycle and to define the role of morphogenesis in relation to virulence, which is largely unknown.

\section{DATA AVAILABILITY STATEMENT}

The original contributions presented in the study are included in the article/supplementary material. Further inquiries can be directed to the corresponding author.

\section{REFERENCES}

Allermann, K., Floto, F., Olsen, J., Sortkjaer, O., and Kier, I. (1978). Sporulation and the Macromolecular Composition of the Mycelium and Arthrospores of Geotrichum Candidum. Physiol. Plant 42 (4), 355-358. doi: 10.1111/j.13993054.1978.tb04095.x

Barbetti, M., and Khangura, R. (2000). Fungal Diseases of Canola in Western Australia. Bulletin 4405, 11-12.

Barbetti, M., and Sivasithamparam, K. (1981). Pseudocercosporella Capsellae and Myrothecium Verrucaria on Rapeseed in Western Australia. Ausytalas. Plant Pathol. 10 (3), 43-44. doi: 10.1071/APP9810043

Barrera, C., and Szaniszlo, P. (1985). Formation and Germination of Fungal Arthroconidia. Crit. Rev. Nicrobiol 12 (4), 271-292. doi: 10.3109/10408418509104431

Bazzigher, G., and Kanzler, E. (1985). Long-term Conservation of Living Fungal Pathogens. Eur. J. For. Pathol. 15 (1), 58-61. doi: 10.1111/j.1439-0329.1985.tb01043.x

Bibel, D., Crumrine, D., Yee, K., and King, R. (1977). Development of Arthrospores of Trichophyton Mentagrophytes. Infect. Immun. 15 (3), 958971. doi: 10.1128/IAI.15.3.958-971.1977

Brun, H., and Tribodet, M. (1991). A Method for Estimate the Level of Resistance in Oilseed Rape to Pseudocercosporella Capsellae. Bull. OILB SROP 14, 64-66.

Cartwright, G., Tanaka, A., Eaton, C., and Scott, B. (2014). Formation of Arthroconidia During Regeneration and Selection of Transformed Epichlö Festucae Protoplasts. Fungal Biol. 118 (5-6), 462-471. doi: 10.1016/ j.funbio.2014.03.004

Cerkauskas, R., Stobbs, L., Lowery, D., Van Driel, L., Liu, W., and VanSchagen, J. (1998). Diseases, Pests, and Abiotic Problems Associated With Oriental Cruciferous Vegetables in Southern Ontario in 1993-1994. Can. J. Plant Pathol. 20 (1), 87-94. doi: 10.1080/07060669809500449

Cissé, O., Almeida, J., Fonseca, Á., Kumar, A., Salojärvi, J., Overmyer, K., et al. (2013). Genome Sequencing of the Plant Pathogen Taphrina Deformans, the Causal Agent of Peach Leaf Curl. MBio 4 (3), e00055-00013. doi: 10.1128/mBio.00055-13

Crossan, D. F. (1954). Cercosporella Leafspot of Crucifers. NC Agric. Exp. Sta. Tech. Bull. 109, 1-23.

Dukik, K., Muñoz, J., Jiang, Y., Feng, P., Sigler, L., Stielow, J., et al. (2017). Novel Taxa of Thermally Dimorphic Systemic Pathogens in the Ajellomycetaceae (Onygenales). Mycoses 60 (5), 296-309. doi: 10.1111/myc.12601

\section{AUTHOR CONTRIBUTIONS}

NG: Designed and conducted the work and drafted the manuscript. PD: Worked with NG to conduct the study and prepared the figures. $\mathrm{SN}, \mathrm{MB}$, and MY: Gave significant contribution to the conception and the design and reviewed the manuscript for critical and important intellectual content. All authors contributed to the article and approved the submitted version.

\section{FUNDING}

Funding support for this research was provided by the School of Plant Biology at the University of Western Australia, and the Centre of Crop Health at the University of Southern Queensland.

\section{ACKNOWLEDGMENTS}

NG is grateful to Dr. Susette Eberhard at the Faculty of Health, Engineering, and Science, The University of Southern Queensland for her exceptional technical support, and to Dr. Dante Adorada at Centre for Crop Health for providing DNA isolation kit.

Duran, A., Uruburu, F., and Villanueva, J. (1973). Morphogenetic and Nutritional Studies of Geotrichum Lactis Cells. Archiv für Mikrobiologie 88 (3), 245-256. doi: $10.1007 / B F 00421849$

Emyanitoff, R., and Hashimoto, T. (1979). The Effects of Temperature, Incubation Atmosphere, and Medium Composition on Arthrospore Formation in the Fungus Trichophyton Mentagrophytes. Can. J. Microbiol. 25 (3), 362-366. doi: 10.1139/m79-056

Fitt, B., Inman, A., Lacey, M., and McCartney, H. (1992). Splash Dispersal of Spores of Pseudocercosporella Capsellae (White Leaf Spot) From Oilseed Rape Leaves of Different Inclination, Flexibility and Age. J. Plant Dis. Prot 99 (3), 234-244.

Gauthier, G. (2015). Dimorphism in Fungal Pathogens of Mammals, Plants, and Insects. PloS Pathog. 11 (2), e1004608. doi: 10.1371/journal.ppat.1004608

Gunasinghe, N., Barbetti, M., You, M., Burrell, D., and Neate, S. (2020). White Leaf Spot Caused by Neopseudocercosporella Capsellae: A Re-Emerging Disease of Brassicaceae. Front. Cell. Infect. Microbiol. 10, 588090. doi: 10.3389/ fcimb. 2020.588090

Gunasinghe, N., You, M., Banga, S., Banga, S., and Barbetti, M. (2017). Outstanding Host Resistance Will Resolve the Threat From White Leaf Spot Disease (Pseudocercosporella Capsellae) to Oilseed and Vegetable Brassica Spp. Crops. Ausytalas. Plant Pathol. 46 (2), 137-146. doi: 10.1007/s13313-017-0470-7

Gunasinghe, N., You, M., Banga, S., and Barbetti, M. (2014). High Level Resistance to Pseudocercosporella Capsellae Offers New Opportunities to Deploy Host Resistance to Effectively Manage White Leaf Spot Disease Across Major Cruciferous Crops. Eur. J. Plant Pathol. 138 (4), 873-890. doi: 10.1007/ s10658-013-0360-y

Gunasinghe, N., You, M., and Barbetti, M. (2016a). Phenotypic and Phylogenetic Studies Associated With the Crucifer White Leaf Spot Pathogen, Pseudocercosporella Capsellae, in Western Australia. Plant Pathol. 65 (2), 205-217. doi: 10.1111/ppa.12402

Gunasinghe, N., You, M., Cawthray, G., and Barbetti, M. (2016b). Cercosporin From Pseudocercosporella Capsellae and its Critical Role in White Leaf Spot Development. Plant Dis. 100 (8), 1521-1531. doi: 10.1094/PDIS-10-15-1192-RE

Gunasinghe, N., You, M., Clode, P., and Barbetti, M. (2016c). Mechanisms of Resistance in Brassica Carinata, B. Ánapus and B. Ájuncea to Pseudocercosporella Capsellae. Plant Pathol. 65 (6), 888-900. doi: 10.1111/ppa.12484 
Gunasinghe, N., You, M., Li, X., Banga, S., Banga, S., and Barbetti, M. (2016d). New Host Resistances to Pseudocercosporella Capsellae and Implications for White Leaf Spot Management in Brassicaceae Crops. Crop Prot 86, 69-76. doi: 10.1016/j.cropro.2016.04.014

Ingold, C. (1995). Blastoconidium Production From Conjugated Basidial Cells in Cintractia. Mycol. Res. 99 (2), 140-142. doi: 10.1016/S0953-7562(09)80877-0

Inman, A., Fitt, B., and Evans, R. (1992). Epidemiology in Relation to Control of White Leaf Spot (Mycosphaerella Capsellae) on Oilseed Rape. GCIRC Bull. 8, 68-75.

Inman, A., Fitt, B., and Evans, R. (1993). White Leaf Spot (Mycosphaerella Capsellae) on Oilseed Rape in the UK? GCIRC Bull. (France) 9, 79-87.

Kier, I., Floto, F., Olsen, J., and Allermann, K. (1980). Macromolecular Composition of the Wall and Protoplasm of Mycelia and Arthrospores of Geotrichum Candidum. Trans. Brit. Mycol. Soc. 75 (3), 355-361. doi: 10.1016/ S0007-1536(80)80113-6

King, D., and Jong, S. (1976). Induction of Arthroconidia in Trichosporon. Mycopathologia 59 (1), 61-63. doi: 10.1007/BF00491208

Kurakado, S., Miyashita, T., Chiba, R., Sato, C., Matsumoto, Y., and Sugita, T. (2020). Role of Arthroconidia in Biofilm Formation by Trichosporon Asahii. Mycoses 64, 42-47. doi: 10.1111/myc.13181

Levy, S., Ziv, N., and Siegal, M. (2012). Bet Hedging in Yeast by Heterogeneous, Age-Correlated Expression of a Stress Protectant. PloS Biol. 10 (5), e1001325. doi: 10.1371/journal.pbio.1001325

Lin, X., Alspaugh, J., Liu, H., and Harris, S. (2015). Fungal Morphogenesis. Cold Spring Harbor Perspect. Med. 5 (2), a019679. doi: 10.1101/cshperspect.a019679

Mayer, F., Wilson, D., and Hube, B. (2013). Candida Albicans Pathogenicity Mechanisms. Virulence 4 (2), 119-128. doi: 10.4161/viru.22913

Mehrabi, R., Zwiers, L., de Waard, M., and Kema, G. (2006). MgHog1 Regulates Dimorphism and Pathogenicity in the Fungal Wheat Pathogen Mycosphaerella Graminicola. Mol. Plant-Microbe Interact. 19 (11), 1262. doi: 10.1094/MPMI-19-1262

Miyazi, M., and Nishimura, K. (1971). Studies on Arthrospore of Trichophyton Rubrum (I). Nihon Ishinkin Gakkai Zasshi 12 (1), 18-23. doi: 10.3314/ jjmm1960.12.18

Moore, R. (1977). Dolipore Disjunction in Antromycopsis Broussonetiae Pat. Exp. Mycol 1 (2), 92-101. doi: 10.1016/S0147-5975(77)80034-0

Murtza, T., You, M., and Barbetti, M. (2018). Understanding White Leaf Spot (Pseudocercosporella Capsellae) Epidemics on Canola. in: AusCanola, 20th Australian Research Assembly on Brassicas (Perth, WA: Australian Oilseeds Federation Inc.). pp. 124-126. Available at: http://australianoilseeds.com/ data/assets/pdf_file/0003/12189/AusCanola_2018_Proceedings_E-book. pdf $\#$ page $=124$.

Murtza, T., You, M., and Barbetti, M. (2021). Canola Growth Stage At Time of Infection Determines Magnitude of White Leaf Spot (Neopseudocercosporella Capsellae) Impact. Plant Dis. doi: 10.1094/PDIS-09-20-2036-RE

Nash, C., and Huber, F. (1971). Antibiotic Synthesis and Morphological Differentiation of Cephalosporium Acremonium. Appl. Microbiol. 22 (1), 610. doi: 10.1128/AM.22.1.6-10.1971

Ocamb, C., Mallory-Smith, C., Thomas, W., Serdani, M., and Putnam, M. (2015). New and Re-Emerging Fungal Pathogens Affecting Brassicaceae Plants in Western Oregon: Black Leg, Light Leaf Spot, and White Leaf Spot. Phytopathology 105, S4.

Odds, F., and Kerridge, D. (1985). Morphogenesis in Candida Albicans. Crit. Rev. Microbiol. 12 (1), 45-93. doi: 10.3109/10408418509104425

Orlowski, M. (1994). Yeast/mycelial dimorphism. In J Wessels and F Meinhardt (Ed.), The Mycota: Growth, Differentiation and Sexuality (Verlag, Berlin: Springer) 1, 143-162.

Palmer, C., and Skinner, W. (2002). Mycosphaerella Graminicola: Latent Infection, Crop Devastation and Genomics. Mol. Plant Pathol. 3 (2), 63-70. doi: 10.1046/ j.1464-6722.2002.00100.x
Penaud, A. (1987). The White Leaf Spot of Crucifers [Pseudocercosporella Capsellae (Ell. Et Ev.)]. Phytoma 385, 23-26.

Penaud, A., and Walker, A. (2015). Oilseed rape pathogens in France. In H Ishii and DW Hollomon (Ed.), Fungicide Resistance in Plant Pathogens: Principles and a Guide to Practical Management (Japan: Springer). pp. 389-399.

Perron, G., and Nourani, D. (1990). Pseuocercosporella Capsellae (Et. Et Ev) Ou Maladies Des Taches Blanches Du Colza. La Defense Des. Vegetaux 44, 22-27.

Petrie, G. (1985). Blackleg and Other Diseases of Canola in Saskatchewan in 1984 and 1985. Can. Plant Dis. Surv 65 (2), 35-41.

Petrie, G., and Vanterpool, T. (1978). Pseudocercosporella Capsellae, the Cause of White Leaf Spot and Grey Stem of Cruciferae in Western Canada. Can. Plant Dis. Surv 58 (4), 69.

Queener, S., and Ellis, L. (1975). Differentiation of Mutants of Cephalosporium Acremoniun in Complex Medium: The Formation of Unicellular Arthrospores and Their Germination. Can. J. Microbiol. 21 (12), 1981-1996. doi: 10.1139/ m75-286

Rippon, J., and Scherr, G. (1959). Induced Dimorphism in Dermatophytes. Mycologia 51 (6), 902-914. doi: 10.1080/00275514.1959.12024871

Rodrigues, M., and Fonseca, A. (2003). Molecular Systematics of the Dimorphic Ascomycete Genus Taphrina. Int. J. Syst. Evol. Microbiol. 53 (2), 607-616. doi: 10.1099/ijs.0.02437-0

Ruiz-Herrera, J., León, C., Guevara-Olvera, L., and Cárabez-Trejo, A. (1995). Yeast-mycelial Dimorphism of Haploid and Diploid Strains of Ustilago Maydis. Microbiology 141 (3), 695-703. doi: 10.1099/13500872-141-3-695

Schneider, C., Rasband, W., and Eliceiri, K. (2012). Nih Image to ImageJ: 25 Years of Image Analysis. Nat. Methods 9 (7), 671-675. doi: 10.1038/nmeth.2089

Sipiczki, M. (2011). Dimorphic Cycle in Candida Citri Sp. Nov., a Novel Yeast Species Isolated From Rotting Fruit in Borneo. FEMS Yeast Res. 11 (2), 202 208. doi: 10.1111/j.1567-1364.2010.00708.x

Takeo, K., and Nishiura, M. (1974). Ultrastructure of Polymorphic Mucor as Observed by Means of Freeze-Etching. Arch. Microbiol. 98 (1), 175-185. doi: 10.1007/BF00425280

Tavares, S., Inacio, J., Fonseca, A., and Oliveira, C. (2004). Direct Detection of Taphrina Deformans on Peach Trees Using Molecular Methods. Eur. J. Plant Pathol. 110, 973-982. doi: 10.1007/s10658-004-4844-7

Van de Wouw, A., Idnurm, A., Davidson, J., Sprague, S., Khangura, R., Ware, A., et al. (2016). Fungal Diseases of Canola in Australia: Identification of Trends, Threats and Potential Therapies. Ausytalas. Plant Pathol. 45 (4), 415-423. doi: 10.1007/s13313-016-0428-1

Vollmeister, E., Schipper, K., Baumann, S., Haag, C., Pohlmann, T., Stock, J., et al. (2012). Fungal Development of the Plant Pathogen Ustilago Maydis. FEMS Microbiol. Rev. 36 (1), 59-77. doi: 10.1111/j.1574-6976.2011.00296.x

Zhu, L., Wang, Y., Zhang, Z., Yang, H., Yan, R., and Zhu, D. (2017). Influence of Environmental and Nutritional Conditions on Yeast-Mycelial Dimorphic Transition in Trichosporon Cutaneum. Biotechnol. Biotechnol. Equip. 31 (3), 516-526. doi: 10.1080/13102818.2017.1292149

Conflict of Interest: The authors declare that the research was conducted in the absence of any commercial or financial relationships that could be construed as a potential conflict of interest.

Copyright (C) 2021 Gunasinghe, Barbetti, You, Dehigaspitiya and Neate. This is an open-access article distributed under the terms of the Creative Commons Attribution License (CC BY). The use, distribution or reproduction in other forums is permitted, provided the original author(s) and the copyright owner(s) are credited and that the original publication in this journal is cited, in accordance with accepted academic practice. No use, distribution or reproduction is permitted which does not comply with these terms. 